\title{
The Relationship between Hyperhomocysteinemia, Haemostatic Factors and Acute Coronary Syndrome in Southeastern Turkey: A Prospective, Comparative Study
}

\author{
Mustafa Yakut ${ }^{1 *}$, Orhan Ayyıldız ${ }^{2}$, Sabri Batum², Sait Alan \\ ${ }^{1}$ Medical Faculty, Ankara University, Ankara, Turkey; ${ }^{2}$ Medical Faculty, Dicle University, Diyarbakır, Turkey. \\ Email: ${ }^{*}$ musyakut@gmail.com.
}

Received March 20 ${ }^{\text {th }}, 2011$; revised May 20 $0^{\text {th }}, 2011$; accepted June $20^{\text {th }}, 2011$.

\begin{abstract}
Aim: We investigated the relationship between hyperhomocysteinemia, coagulation factors and acute coronary syndrome. Materials and method: The study was conducted at cardiology and hematology department of Dicle University Medical School between January $1^{\text {st }} 2003$ and May $31^{\text {st }}$ 2009. The study included 96 patients with acute coronary syndrome and 96 controls. Results: Baseline characteristics of patients (63 males, 33 females, mean age: 56.4 years) and controls (58 males and 38 females, mean age: 51.1 years) were similar. There was a statistically significant difference between two groups according to homocysteine levels $(13.4 \pm 8.0$ micromole/L vs. $12.8 \pm 7.1$ micromole/L $p=0.042)$. In this study, we found that hyperhomocysteinemia, smoking, elevated levels of CRP, low levels of HDL, positive family history, presence of hypertension, BMI $>27$, low levels of protein $C$ and protein $S$ were associated with high risk for acute coronary syndrome. Fibrinogen level, factor V level, factor VIII level, factor IX level, factor X level, and factor V leiden $(p=0.128)$ are not risk factors for acute coronary syndrome. Conclusion: Hyperhomocysteine is a significant risk factor for acute coronary syndrome. There is not relationship between coagulation factors and acute coronary syndrome except low levels of protein $C$ and protein $S$.
\end{abstract}

Keywords: Hyperhomocysteinemia, Coagulation Factors, Acute Coronary Syndrome

\section{Introduction}

Atherosclerosis is the most common cause of death worldwide [1]. Atherosclerosis is considered to be a pathophysiologic process that leads to several diseases like coronary artery disease, cerebrovascular disease, carotid artery disease and peripheral artery disease.

Coronary atherosclerosis begins at early stages of life. Atherosclerosis is present histologically in most of young adults, but years are required for maturation of atherosclerotic plaques to cause ischemic heart diseases. Proliferation of smooth muscle cells, increase in matrix synthesis and lipid deposition lead to narrowing of coronary arteries. Infiltration of the intima with lipids and inflammatory cells causes various degrees of fibrosis [2]. If erosion or tear does not occur at the surfaces of these fibrotic areas, the patients experience stable angina pectoris; if plaque rupture or erosion occurs, life threatening clinical conditions that are known as acute coro- nary syndromes may develop.

The association between acute coronary syndrome and various risk factors like age, gender, smoking, elevated CRP levels, inflammation, diabetes, low HDL levels and dyslipidemia, systemic hypertension, obesity, family history, socio-economical status, physical inactivity, coagulation factors, lipoprotein a, PAF1 and plasma homocysteine levels is defined in many studies [3].

The coexistence of premature atherosclerosis and arterial thrombosis with severe homocysteinemia was first described by Mc Cully and colleagues in 1969 [4]. However, mild to moderate elevations in homocysteine levels were reported recently to be risk factors for atherosclerosis and thrombosis. Moderate elevations at homocysteine levels were shown to be associated with an increase the risk for coronary artery disease in many studies [5-9]. Homocysteine provides a suitable back- 
ground for atherosclerosis by impairing the mechanisms of coagulation-fibrinolysis, endothelial functions and proliferation of smooth muscle cells. In addition, increased thromboxan A2 and decreased prostacyclin cause increase in aggregation of platelets. The relationship between the coagulation factors and heart diseases is shown in many studies. In addition, homocysteine provides a background for atherosclerosis by leading to various impairments in coagulation factors like activetion of factor XII, decreased ATIII levels, activation of factor $\mathrm{V}$, decreased activation of protein $\mathrm{C}$, decrease in production and activation of thrombomodulin, increased affinity of lipoprotein a to fibrin and inhibition of vWF. In addition, oxidative arterial damage and impaired endothelial vasomotor regulation cause change of coagulation and endothelial thromboembolic events [10].

In this study, we investigated the risk factors for acute coronary syndrome, particularly hyperhomocysteinemia, coagulation factors (protein $\mathrm{C}$, protein $\mathrm{S}$, fibrinogen, factor V, factor VIII, factor IX, factor X and factor V) leiden mutation in people living in Southeast of Turkey.

\section{Materials and Methods}

\subsection{Study Centre}

The study was performed between January 2003-May 2009 at Dicle University Medical School, Department of Cardiology and Hematology Unit which is the reference centre for follow up of acute coronary syndrome and hematology laboratory.

\subsection{Patients Group}

A total of 96 patients (33 females and 63 males) were included in the study without any age restriction; 75 patients had acute myocardial infarction and 21 patients were diagnosed as unstable angina pectoris. The diagnosis of acute myocardial infarction (MI) depended on the presence of ST segment elevation $>2 \mathrm{~mm}$ at least two consecutive derivations in the Eectrocardiyogram (ECG), besides elevation of cardiac enzymes; 32 patients had inferior MI and 43 patients had anterior MI. Unstable angina pectoris (UAP) diagnosis was established according to the presence of ST segment depression or negativity of T-wave at ECG, plus elevation in troponin-I levels; there were 21 patients with UAP. The patients were included in the study following a mean period of 48 hours which they were in the intensive care unit.

\subsection{Control Group}

A total of 96 healthy subjects ( 38 females and 58 males), who were admitted to outpatient clinics of Dicle University Medical School, Department of Internal Medicine, who did not have any history for coronary artery disease and whose physical examination, ECG and chest x-ray findings were normal constituted the control group. Both groups were similar according to ages and genders of the subjects (the mean age was 51.15 in controls and 56.41 in patients).

\subsection{Other Characteristics of the Participant}

All participants were questioned about the age, gender, family history and CAD history. When evaluating the patients for obesity the criteria of World Health Organization (WHO) were taken into consideration. The participants whose BMI measurements were between 25 29.9 were accepted as weight excess, whose BMI $\geq 30$ were accepted as obese and whose BMI $\geq 40$ were accepted as morbid obese. The history for smoking was questioned as well. The duration of smoking was determined. The presence of hypertension was investigated. The subjects whose fasting blood glucose levels were higher than $126 \mathrm{mg} / \mathrm{dl}$ and/or postprandial (120 min.) blood glucose levels were higher than $200 \mathrm{mg} / \mathrm{dl}$ were considered to be diabetic.

\subsection{Laboratory Evaluations}

In order to evaluate the level of homocysteine, 3 - $4 \mathrm{cc}$ blood sample from antecubital vein was taken from all patients and healthy controls into $4.5 \mathrm{cc}$ tubes with EDTA. Abbott Aeroset Toshiba auto analyzer was used in order to measure the levels of total cholesterol, HDL-cholesterol, LDL-cholesterol and triglycerides as $\mathrm{mg} / \mathrm{dl}$. In order to measure the levels vitamin B12 (pg/ml) and folic acid $(\mathrm{ng} / \mathrm{ml}), 6-7 \mathrm{cc}$ blood samples was taken into biochemical tubes with gel and these samples were analyzed via Roche Hitachi Modular E170 tool. In addition, 4 - 5 cc blood sample was taken into $5 \mathrm{cc}$ blood tubes to evaluate the levels of CRP $(\mathrm{mg} / \mathrm{dl})$, factor V (\%), factor VIII (\%), factor IX (\%), factor XII (\%), protein C, protein $\mathrm{S}$ and APC resistance and these samples were studied with Instrumentation Laboratory Coagulation Kit and ACL Advance Coagulometry tool. Furthermore, factor V mutation was evaluated with Light Cycler polymerase chain reaction (PCR) from the blood that was taken into complete blood tube with EDTA.

\subsection{Measurement of Homocysteine}

The levels of total homocysteine in blood samples were measured with immunoassay method by using Immulite Homocysteine analyzer (PILKHO-5, 2002-06-19). Homocyteine in plasma or serum was separated from binding protein and was incubated at $37^{\circ} \mathrm{C}$ for 30 minutes. Then it was converted to S-adenosyl-L-Homocysteine (SAH) by S-adenosyl-L-Homocysteine hydrolase and 
dithiothretiol (DTT). The basis of measurement method was the conversion of homocysteine to S-adenosyl-LHomocysteine (SAH) and the measurement of S-adenosyl-L-Homocysteine (SAH) via enzyme-linked immunoassay method.

\subsection{Statistical Methods}

Statistical analyses were performed with SPSS 16.0 software. Comparison of categorical variants was performed with chi-square (Fischer's exact test) and Student- $t$ test was used in comparison of numeric variants of two groups. The level of statistical significance was accepted as $p<0.05$. Quantitative values of patients and controls were expressed as mean \pm standard deviation and qualitative values were expressed as percentage. An error level of 0.05 was taken into consideration.

\section{Results}

The study included a total of 192 participants (96 patients with coronary artery disease and 96 healthy controls. The mean age of patients was 56.41 years (range, 34 - 85 years) and of controls was 51.15 years (range 26 - 76 years). There was not any difference between two groups according to age and gender $(p>0.05)$ (Table 1).

We determined plasma homocysteine level as $13.4 \pm$ 8.0 micromole/L in patients group and as $12.8 \pm 7.1$ micromole/L in controls (Table 1). The frequency of homocysteinemia was 2.34 times higher in CAD group than controls $(p=0.019, \mathrm{OR}=2.34)$ (Tables 2 and 6). The levels of plasma vitamin B12 was found to be significantly low in individuals whose plasma homocysteine levels were elevated $(p<0.05)$ (Table 3).

Hyperhomocysteinemia, smoking, elevated levels of CRP, low levels of HDL, positive family history, presence of hypertension, BMI $>27$, low levels of protein C and protein $\mathrm{S}$ were found to be statistically significant higher in CAD group than controls (Tables 4 and 5). There was not any statistically significant difference between two groups according to total cholesterol level $(p>0.05)$, LDL-cholesterol $(p=0.839)$, triglyceride $(p$ $>0.05)$, fibrinogen level $(p=0.05)$, factor $\mathrm{V}$ level $(p=$ $0.214)$, factor V leiden mutation ( $p=0,128)$, factor VIII level $(p=0.208)$, factor IX level $(p=0.457)$, factor X

Table 1. The distribution of ages, genders, and plasma level of homocysteine in patients and controls.

\begin{tabular}{llll}
\hline & Control Group & CAD group & $P$ value \\
\hline$n$ & 96 & 96 & \\
Age $($ mean \pm SD) & $56.4 \pm 12.14$ & $51.15 \pm 11.87$ & NS \\
& $(34-85)$ & $(32-76)$ & \\
Gender & $38(53.5 \%)$ female & $33(46.5 \%)$ female & NS \\
& $58(47.9 \%)$ male & $63(52.1 \%)$ male & \\
Homocysteine & $13.4 \pm 8.0$ & $13.4 \pm 8.0$ & 0.042 \\
\hline
\end{tabular}

Table 2. The comparison of two groups according to low, normal and high homocysteine levels.

\begin{tabular}{|c|c|c|c|c|c|c|}
\hline & \multicolumn{6}{|c|}{ The level of homocysteine } \\
\hline & \multicolumn{2}{|c|}{$\begin{array}{c}\text { Elevated } \\
\text { homocysteine } \\
\text { levels } \\
\end{array}$} & \multicolumn{2}{|c|}{$\begin{array}{c}\text { Normal } \\
\text { homocysteine } \\
\text { levels }\end{array}$} & \multicolumn{2}{|c|}{$\begin{array}{c}\text { Low } \\
\text { homocysteine } \\
\text { levels }\end{array}$} \\
\hline & $n$ & $(\%)$ & $n$ & $(\%)$ & $n$ & $(\%)$ \\
\hline $\begin{array}{l}\text { Patient } \\
\text { group }\end{array}$ & 47 & 48.9 & 45 & 46.8 & 4 & 4.1 \\
\hline $\begin{array}{l}\text { Control } \\
\text { group }\end{array}$ & 28 & 29.1 & 63 & 65.6 & 3 & 3.1 \\
\hline Total & 108 & 100 & 75 & 100 & 7 & 100 \\
\hline
\end{tabular}

Table 3. The relation between hyperhomocysteinemia and vitamin B12 levels.

\begin{tabular}{lcccc}
\hline \multirow{2}{*}{ Vit B12 } & \multicolumn{4}{c}{ Homocysteine } \\
\cline { 2 - 5 } & Normal & Elevated & Low & Total \\
\hline Normal & 89 & 29 & 4 & 122 \\
Elevated & 3 & 3 & & 6 \\
Low & 13 & 38 & 2 & 53 \\
Total & 105 & 70 & 6 & 181
\end{tabular}

Table 4. Evaluation of patient and control groups with respect to protein $S$.

\begin{tabular}{lcccccccc}
\hline & \multicolumn{9}{c}{ Protein S levels } & \multirow{2}{*}{ Total } \\
\cline { 2 - 7 } & \multicolumn{2}{c}{ Low } & \multicolumn{2}{c}{ Normal } & \multicolumn{2}{c}{ Elevated } & \multicolumn{2}{c}{} \\
\cline { 2 - 7 } & $n$ & $(\%)$ & $n$ & $(\%)$ & $n$ & $(\%)$ & $n$ & $(\%)$ \\
\hline Patients & 12 & 75 & 69 & 43.4 & 2 & 66.7 & 69 & 43.4 \\
Controls & 4 & 25 & 90 & 56.6 & 1 & 33.3 & 95 & 53.4 \\
Total & 159 & 100 & 16 & 100 & 3 & 100 & 178 & 100 \\
\hline
\end{tabular}

Table 5. Evaluation of patient and control groups with respect to protein $\mathrm{C}$.

\begin{tabular}{|c|c|c|c|c|}
\hline & \multicolumn{4}{|c|}{ Protein C levels } \\
\hline & \multicolumn{2}{|c|}{ Low } & \multicolumn{2}{|c|}{ Normal } \\
\hline & $\mathrm{n}$ & $(\%)$ & $\mathrm{n}$ & $(\%)$ \\
\hline Patients & 40 & 69 & 43 & 35,8 \\
\hline Controls & 18 & 39 & 18 & 31,0 \\
\hline Total & 159 & 100 & 120 & 100 \\
\hline
\end{tabular}

level $(p=0.205)$, gender $(p=0.550)$ and the presence of menopause in females $(p>0.05)$. In addition, there was not any correlation between vitamin B12 $(p=0.083)$ and folic acid $(p=0.619)$ levels and increase CAD risk. But there was a relationship between low vitamin B12 levels and high homocysteine levels (Table 6).

\section{Discussion}

The incidence of hyperhomocysteinemia was reported as $5 \%$ in general population and as $13 \%-47 \%$ in individuals with symptomatic atherosclerotic disease. Normally fasting plasma total homocysteine level is below 15 micromole/L [12]. Plasma homocysteine level between 15 - 30 micromole/L is defined as mild, between 31 100 micromole/L is defined as moderate and above 100 
Table 6. Risk factors for CAD.

\begin{tabular}{lll}
\hline Risk Factor & $\boldsymbol{p}$ & OR \\
\hline Elevated plasma homocysteine level & $p=0.019$ & 2.34 \\
Smoking & $p<0.05$ & 3.1 \\
Presence of hypertension & $p<0.05$ & 6.1 \\
Positive family history & $P=0.017$ & 4.6 \\
Elevated CRP levels & $p<0.05$ & 4.6 \\
BMI $>$ 27 & $p=0.008$ & 4.6 \\
HDL $<35$ mg/dl & $p<0.05$ & 4.1 \\
Low levels of protein S & $p=0.042$ & 3.9 \\
Low levels of protein C & $p=0.013$ & 3.9 \\
Gender & $p=0.550$ & \\
Presence of menopause in females & $p>0.05$ & \\
Elevated total cholesterol levels & $p>0.05$ & \\
Elevated LDL-cholesterol levels & $p=0.839$ & \\
Elevated triglycerides & $p>0.05$ & \\
Fibrinogen level & $p=0.510$ & \\
Factor V level & $P=0.214$ & \\
Factor VIII level & $p=0.208$ & \\
Factor IX level & $p=0.457$ & \\
Factor X level & $p=0.208$ & \\
Factor V leiden mutation & $p=0.128$ \\
Vitamin B12 level & $p=0.083$ \\
Folic acid level & $p=0.619$ & \\
\hline
\end{tabular}

micromole/L is defined as severe hyperhomocysteinemia [13]. The risk for coronary artery disease was found 2.6 times higher in individuals whose homocysteine levels were higher than 12.2 micromole/L [14]. This relationship was reported to be more powerful in especially individuals with plasma homocysteine levels higher than 15 micromole/L $[15,16,23]$. Boushey and colleagues have demonstrated that there was a linear association between vascular disease and homocysteine level. Five micromole/L elevations in homocysteine levels were found to increase the risk for vascular disease $1 / 3$ times more [17].

It was proposed that homocysteine levels were affected by acute phase reactants and that was the reason for high homocysteine levels at blood samples that were obtained at acute period. But it was shown later that homocysteine levels did not differ significantly during acute myocardial infarction [18].

There were many prospective cohort studies (Physicians Health Study-BUPA, UK-Tromso, Norway-British Regional-Nygard, Belgium-Physicians Health-MRFIT, USA-North Karelia Project-ARIC, USA) that revealed an association between hyperhomocysteinemia and vascular diseases [19-21]. Boushey and colleagues performed a meta-analysis and evaluated 4000 patients in 27 cross-sectional and retrospective studies. They found a powerful correlation between atherosclerotic vascular disease and homocysteine levels in patients with angiographically proven coronary artery disease [17].

The Large European Collaborative Study supported the findings of Boushey et al in their analysis of more than 40 studies [16]. Hyperhomocysteinemia increases the risk for coronary artery disease more in the presence of any other risk factor like smoking or hypercholesterolemia. We found a statistically significant correlation between elevated homocysteine levels and coronary artery disease $(p=0.019)$. Plasma homocysteine levels were higher in CAD group than controls. Mild to moderate hyperhomocysteinemia is an independent risk factor for coronary, cerebral and peripheral atherosclerosis $[2,25]$. The risk for stroke and MI increases in elderly people in relation with total homocysteine levels. Each 1 micromole/L increase in total homocysteine level leads to a linear $6 \%-7 \%$ increase in the risk for stroke and MI [22]. The meta-analysis of many studies revealed that fasting homocysteine levels were positively correlated with recurrent venous thrombosis. Moreover, many studies reported that hyperhomocysteinemia was an independent risk factor for deep vein thrombosis [23-28].

MTFHR mutation is often at the nucleotide 677 between $\mathrm{C}$ and $\mathrm{T}[29,30]$. In people with homozygous MTFHR mutation, the decrease in folic acid levels increases the risk of vascular atherosclerotic disease [31]. The risk for hyperhomocysteinemia increases with the deficiency of folic acid, vitamin B6 and vitamin B12 $[32,33]$. We did not find any correlation between the levels of vitamin B12 $(p=0.083)$ or folic acid $(p=0.619)$ and increased risk for CAD. But there was a significant asso- ciation between the decrease in vitamin B12 levels and the increase in homocysteine levels $(p<0.05)$. It was reported in a meta-analysis of 12 randomized, controlled studies conducted with 1114 patients that daily folic acid supplementation positively effected homocysteine levels $(25 \%$ decrease in homocysteine levels with supplementa- tion of folic acid at a daily dose of $0.5-5$ $\mathrm{mg}$ and $7 \%$ decrease in homocysteine levels with supplementation of vitamin B12 at a daily dose of $0.5 \mathrm{mg}$ ) [34].

The presence of obstructing thrombus was shown in almost all patients with acute myocardial infarction and in necropsy materials of sudden cardiac deaths. Thus there is not any suspicion about the role of haemostatic factors in pathophysiology of the disease. The relation between plasma fibrinogen level and cardiac disease was shown in many studies [35-37]. We did not find any statistically significant difference between two groups according to fibrinogen level $(p=0.05)$, factor V level ( $p=$ $0.214)$, factor VIII level $(p=0.208)$, factor IX level $(p=$ $0.457)$, factor $\mathrm{X}$ level $(p=0.205)$, and factor V level ( $p$ $=0.128)$. There is a significant correlation between the deficiencies of protein $\mathrm{C}$ and $\mathrm{S}$ and the increase in the risk for deep vein thrombosis. Nonetheless, there is a general suggestion that the deficiencies of these proteins were not a predisposing factor for arterial thrombosis 
[38]. However, it was reported in some clinical studies that the risk for AMI increased in individuals with elevated plasma procoagulant levels [39]. We found protein $\mathrm{S}(p=0.42)$ and protein $\mathrm{C}(p=0.130)$ levels significantly low in CAD group than controls.

In this study, we found that hyperhomocysteinemia, smoking, elevated levels of CRP, low levels of HDL, positive family history, presence of hypertension, BMI > 27 , low levels of protein $C$ and protein $S$ were associated with high risk for acute coronary syndrome. Fibrinogen level, factor V level, factor VIII level, factor IX level, factor X level, and factor V level $(p=0.128)$ are not risk factors for acute coronary syndrome.

In conclusion, we found that hyperhomocysteine is a significant risk factor for acute coronary syndrome. Except low levels of protein $\mathrm{C}$ and protein $\mathrm{S}$, there is not relationship between coagulation factors and acute coronary syndrome.

\section{REFERENCES}

[1] World Health Organization, "The World Health Report 1999: Making a Difference,” WHO, Geneva, 1999.

[2] C. J. Murray, A. D. Lopez, "Global Mortality Disability, and Contribution of Risk Factors: Global Burden Odf Disease Study," Lancet, Vol. 349, 1997, pp. 1436-1442. doi:10.1016/S0140-6736(96)07495-8

[3] P. Libby, R. O. Bonow, D. L. Mann and D. P. Zipes, "Braunwald's Heart Disease: A Textbook of Cardiovascular Medicine," 8th Edition, Saunders, Philadelphia, 2005.

[4] K. S. McCully, "Vascular Pathology of Homocysteinemia, Implications for the Pathogenesis of Arteriosclerosis," The American Journal of Pathology, Vol. 56, 1969, pp. $1-28$.

[5] T. Katic, I. Sakic and M. Bergovec, "Primary Prevention of Cardiovascular Disease," Acta Medica Croatica, Vol. 63, No. 1, 2009, pp. 71-74.

[6] S. Sacco and A. Carolei, "Homocysteine and Stroke: Another Brick in the Wall," Clinical Science (Lond), Vol. 118, No. 3, 2009, pp. 183-185.

[7] A. S. Wierzbicki, "Homocysteine and Cardiovascular Disease: A Review of the Evidence," Diabetes and Vascular Disease Research, Vol. 4, No. 2, 2007, pp. 143150. doi:10.3132/dvdr.2007.033

[8] M. G. Van Oijen, B. E. Claessen, N. Clappers, A. Van Schaik, R. J. Laheij, J. B. Lansen, W. H. Peters and F. W. Verheugt, "Prognostic Value of Free Plasma Homocysteine Levels in Patients Hospitalized with Acute Coronary Syndrome," The American Journal of Cardiology, Vol. 102, No. 2, 2008, pp. 135-139.

[9] M. L. Cheng, H. Y. Ho, J. F. Lin, Y. C. Chen, E. C. Chan and D. T. Chiu, "Clinical Relevance of Plasma Homocysteine Levels in Taiwanese Patients with Coronary
Artery Disease," Biofactors, Vol. 34, No. 2, 2008, pp. 125-134. doi:10.1002/biof.5520340204

[10] G. N. Welch, G. Upchurch Jr., J. Loscalzo, "HyperhomoCysteinemia and Atherotrombosis," Annals of the New York Academy of Sciences, Vol. 811, 1997, pp. 48-58. doi:10.1111/j.1749-6632.1997.tb51988.x

[11] M. R. Nehler, L. M. Taylor and J. M. Porter, "Homocysteine as a Risc Factor for Atherosclerosis: A Review," Cardiovascular Pathology, Vol. 6, No. 1, 1997, pp. 1-9. doi:10.1016/S1054-8807(96)00064-6

[12] P. M. Ueland, H. Refsum, S. P. Stabler, M. R. Malinow, A. Andersson and R. H. Allen, "Total Homocysteine in Plasma or Serum," Clinical Chemistry, Vol. 39, No. 9, 1993, pp. 1764-1779.

[13] S. S. Kang, P. W. K. Wong and M. R. Malinow, "Hyperhomocyst(e)inemia as a Risk Factor for Occlusive Vascular Disease," Annual Review of Nutrition, Vol. 12, 1992, pp. 279-298. doi:10.1146/annurev.nu.12.070192.001431

[14] P. J. Stubbs, M. K. Al-Obaidi, R. M. Conory and P. O. Collinson, "Effects of Plasma Homocysteine Concentration on Early and Late Events in Patients with Acute Coronary Sendromes," Circulation, Vol. 102, No. 2, 2000, pp. 605-610.

[15] O. Nygard, J. E. Nordrehaug, H. Refsum, et al., "Plasma Homocysteine Levels and Mortality in Patients with Coronary Artery Disease," The New England Journal of Medicine, Vol. 337, 1997, pp. 230-236. doi:10.1056/NEJM199707243370403

[16] O. Torbjorn, S. Antia, H. Marianne, et al., "Serum Homocysteine Concentration as a İndicator of Survival in Patients with Acute Coronary Sendroms," Archives of Internal Medicine, Vol. 160, No. 12, 2000, pp. 1834-1840. doi:10.1001/archinte.160.12.1834

[17] C. J. Boushey, S. A. A. Beresford, G. S. Omenn and A. G. Motoulsky, "A Quantitative Assesment of Plasma Homocysteine as a Risc Factor for Vasculer Disease: Probable Benefits of İncreasing Folic Asit İntake," The Journal of the American Medical Association, Vol. 274, No. 13, 1995, pp. 1049-1057. doi:10.1001/jama.274.13.1049

[18] U. C. Garg, Z. J. Zheng, A. R. Folsom, Y. S. Moyer, M. Y. Tsai, P. McGovern and J. H. Eckfeldt, "Short-Term and Long-Term Variability of Plasma Homocysteine Measurement," Clinical Chemistry, Vol. 43, No. 1, 1997, pp. 141-145

[19] L. M. Taylor Jr., R. D. de Frang and E. J. Harris Jr., "The Association of Elevated Plasma Homocysteine with Progression of Symptomatic Peripheral Arterial Disease," Journal of Vascular Surgery, Vol. 13, No. 1, 1991, pp. 128-136. doi:10.1067/mva.1991.24913

[20] I. M. Graham, L. E. Daly , H. M. Refsum, et al., "Plasma Homocysteine as a Risk Factor for Vascular Disease: The European Concerted Action Project," The Journal of the American Medical Association, Vol. 277, No. 2, 1997, pp. 1775-1781. doi:10.1001/jama.277.22.1775 
[21] A. Majors, L. A. Ehrhart, E. H. Pezacka, "Homocysteine as a Risk Factor for Vascular Disease Enhanced Collagen Production and Accumulation by Smooth Muscle Cells," Arteriosclerosis, Thrombosis, and Vascular Biology, Vol. 17, 1997, pp. 2074-2081. doi:10.1161/01.ATV.17.10.2074

[22] M. Boats, L. Launer, J. Lindermans, et al., "Homocysteine and Short-Term Risk of MI and Stroke in the Elderly," Archives of Internal Medicine, Vol. 159, 1999, pp. 38-44. doi:10.1001/archinte.159.1.38

[23] J. G. Ray, "Meta-Analysis of Hyperhomocysteinemia as Arisk Factor for Venous Thromboembolic Disease," Archives of Internal Medicine, Vol. 158, 1998, pp. 21012116. doi:10.1001/archinte.158.19.2101

[24] P. M. Ridker, C. H. Hennekens, J. Selhub, J. P. Miletich, M. R. Malinow and M. J. Stampfer, "Interrelation of Hyperhomocyst(e)inemia, Factor V Leiden, and Risks of Future Venous Thromboembolism," Circulation, Vol. 95, No. 7, 1997, pp. 1777-1782.

[25] T. H. Martın, K. Ted, J. H. Blom, et al., "Hiperhomocysteinemia as a Risk Factor for Deep-Vein Thrombosis," The New England Journal of Medicine, Vol. 334, 1996, pp. 759-625. doi:10.1056/NEJM199603213341203

[26] G. H. J. Boers, A. G. H. Smals, F. J. M. Trijbels, et al., "Heterozygosity for Homocystinuria in Premature Peripheral and Cerebral Occlusive Arterial Disease," The New England Journal of Medicine, Vol. 313, 1985, pp. 709715. doi:10.1056/NEJM198509193131201

[27] J. Selhub, P. F. Jacques, A. G. Bostom, et al., "Association between Plasma Homocysteine Concentrations and Extracranial Carotid-Artery Stenosis," The New England Journal of Medicine, Vol. 332, 1995, pp. 286-291. doi:10.1056/NEJM199502023320502

[28] R. Clarke, L. Daly, K. Robinson, et al., "HyperhomoCysteinemia an Independent Risk Factor for Vascular Disease," The New England Journal of Medicine, Vol. 324, 1991, pp. 1149-1155. doi:10.1056/NEJM199104253241701

[29] P. Frosst, H. J. Bloom, R. Milos, et al., "A Canditate Genetic Risk Factor for Vasculer Disease: A Common Mutation in MTHFR," Nature Genetics, Vol. 10, 1995, pp. 111-113. doi:10.1038/ng0595-111

[30] T. G. Deloughery, A. Evans, A. Sadeghi, et al., "Common Mutation in MTHFR: Correlation with Homocysteine Metabolism and Late Onset Vasculer Disease," Circulation, Vol. 94, No. 12, 1996, pp. 3074-3078.

[31] S. H. Mudd, F. Skovby , H. L. Levy, et al., "The Natural
History of Homocystinuria Due to Cystathionine Beta Synthase Deficiency," The American Journal of Human Genetics, Vol. 37, No. 1, 1985, pp. 1-31.

[32] J. Selhub, P. F. Jacques, P. W. Wilson and D. Rush, "Vitamine Status and Intake as Primary Determinants of Homocysteinemia in an Elderly Population," The Journal of the American Medical Association, Vol. 270, No. 22, 1993, pp. 2693-2698. doi:10.1001/jama.270.22.2693

[33] S. S. Kang, P. W. Wong and M. Norusis, "Homocysteinemia Due to Folate Deficiency," Metabolism, Vol. 36, No. 5, 1987, pp. 458-462. doi:10.1016/0026-0495(87)90043-6

[34] R. Clarke and R. Collins, "Can Dietary Supplements with Folic Acid or Vitamin B6 Reduce Cardiovascular Risk?" Journal of Cardiovascular Risk, Vol. 5, 1998, pp. 249255. doi:10.1097/00043798-199808000-00007

[35] B. Cantin, J.-P. Despres, B. Lamarche, S. Mooriani, et al., "Association of Fibrinogen and Lipoprotein(a) as a Coronary Heart Disease Risk Factor in Men (The Quebec Cardiovascular Study)," Journal of Cardiovascular Risk, Vol. 89, No. 6, 2002, pp. 662-666. doi:10.1016/S0002-9149(01)02336-0

[36] K. Krobot, H. W. Hense, P. Cremer, et al., "Determinents of Plasma Fibrinogen: Relatıon to Body Weight, Waist to Hip Rat1o, Smoking, Alcohol, Age, Sex, Result from the Second Monica Augsburg Survey, 1989/1990," Arteriosclerosis, Thrombosis, and Vascular Biology, Vol. 12, 1992, pp. 780-788. doi:10.1161/01.ATV.12.7.780

[37] A. Onat, G. Hergenç, B. Yıldırım, et al., "Türk Erişkinlerde Kanda Fibrinojen dÜzeyi ve Bazı Risk Parametreleri İle İlişkis," Türk Kardiyoloji Derneği Arşivi, Vol. 28, 2000, pp. 115-120.

[38] M. Graves and F. Preston, "The Hypercoagulable State in Clinical Practice," British Journal of Haematology, Vol. 79, No. 2, 1991, pp. 148-151. doi:10.1111/j.1365-2141.1991.tb04514.x

[39] A. Undas, K. Szudrzy, et al., "Systemic Blood Coagulation Activation in Acute Coronary Syndromes," Blood, Vol. 113, No. 9, 2009, pp. 2070-2078. doi:10.1182/blood-2008-07-167411

[40] K. M. Pelkonen, U. Wartiovaara-Kautto, M. S. Nieminen, et al., "Low Normal Level of Protein $\mathrm{C}$ or of Antithrombin Increases Risk for Recurrent Cardiovascular Events," Blood Coagul Fibrinolysis, Vol. 16, No. 4, 2005, pp. $275-280$ doi:10.1097/01.mbc.0000169220.00679.13 